\section{In memory of Leonardo Corcos}

Leonardo Corcos, surgeon in Florence, has certainly been one of the most known Italian phlebologists over the last thirty years. He lived in Fiesole, with the wife Annalisa and two sons, in an ancient villa above the hills. In this magic place he cultivated the olive as well his passions. Leonardo gave numerous contributions to Phlebology. From a technical point of view, he updated and improved some surgical instruments, such as the old Thompson's external strippers and the Albanese's spatula. ${ }^{1} \mathrm{He}$ was one of the protagonists of the Italian season of the terminal valve repair, with external prosthesis, of the great saphenous vein. This was a subject that was passionate for many surgeons between the 80 's and the 90's.,3 Furthermore, it was also very dedicated to the understanding of biological mechanisms that lead to saphenous laser ablation. ${ }^{4}$

Veins and Lymphatics was honoured to issue one of the latest Leonardo's papers on Doppler venous pressure index measurements, a subject that he cultivated particularly. ${ }^{5}$

Leonardo was an eclectic man of genius. He loved music and was an excel- lent pianist. As a young man he had also played in a rock group, which was inspired by the Genesis. Many of us remind him playing the piano and singing in some congress of the world, improvising and enjoying the other delegates. And so on the piano, smoking his beloved Tuscan cigar we want to remember Leonardo.

Paolo Zamboni, University of Ferrara, Italy paolozamboni@icloud.com

\section{References}

1. Peruzzi G, Romeo V, Corcos L. Malleable spatulas in surgery of primary and secondary varices of the legs]. Angiologia 1990;4:38-41.

2. Corcos L, De Anna D, Zamboni P, et al. Reparative surgery of valves in the treatment of superficial venous insufficiency. External banding valvuloplasty versus high ligation or disconnection. A prospective multicentric trial. J Mal Vasc 1997;22:128-36.

3. Corcos L, Peruzzi GP, Romeo V, et al. [External valvuloplasty of the saphenofemoral junction]. Phlebologie

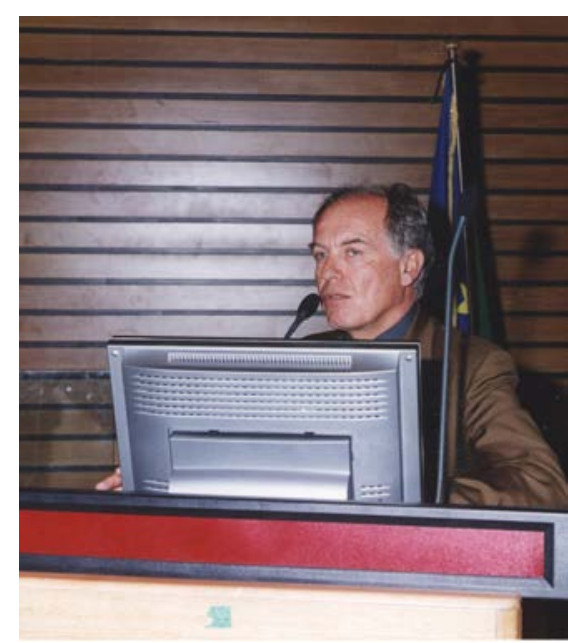

1991;44:497-508.

4. Corcos L, Dini S, De Anna D, et al. The immediate effects of endovenous diode $808-\mathrm{nm}$ laser in the greater saphenous vein: morphologic study and clinical implications. J Vasc Surg 2005;41: 1018-24; discussion 1025.

5. Corcos L, Pontello D, Spina T. Elastic compression treatment of chronic superficial venous insufficiency of the lower limbs based on Doppler venous pressure index measurements. Veins and Lymphatics 2015;4:2230. 